\title{
Modality Analysis of the Newspaper Articles about the Scottish Ship RMS Queen Elizabeth
}

\author{
Dr. Puteri Zarina Binti Megat Khalid \\ Universiti Kuala Lumpur Malaysian Institute of Marine Engineering Technology \\ (UnikI MIMET), Lumut, Malaysia \\ puterizarina@mimet.unikl.edu.my, putriana71@yahoo.com
}

Doi:10.5901/ajis.2013.v2n9p458

\begin{abstract}
Newspaper articles are commonly devoid of any authorial presence as they normally attempt to provide the aura of objectivity (McCabe and Heilman, 2007, p. 148). Bearing this in mind, this study was conducted to examine the traces of authorial subjectivity in four categories of news articles published in Scotland. These articles were published in 1938 in three news broadsheets. The traces of authorial subjectivity were analysed from the use of modal verbs by the authors. I am particularly interested in examining the modal markers through the use of modal verbs that writers use to inject their subjective voices into the texts with the purpose of 'entertaining' dialogic alternatives with the readership. To serve this purpose, the appraisal framework propounded by Martin and White (2005) and Halliday's (2004) notion of Mood and modality system were employed in the analysis of the resources of 'engagement'. In the lexico-grammatical analysis of the newspaper articles, it was found that the Mood and modality systems expressing the interpersonal meaning of the texts were present in both independent clauses and dependent clauses in all four categories of news in the corpus. It was also found that all the clauses are in the declarative, suggesting an informative nature of the texts. In addition, the news writers also employed numerous modal verbs in presenting their subjective authorial positioning in the otherwise neutral journalistic texts.
\end{abstract}

Keywords: modality, authorial subjectivity, modal verbs, interpersonal meaning

\section{Introduction}

An author may choose to deliver his/her intended message from various grammatical tools in the written language (McCabe and Heilman, 2007, p. 139). Newspapers is one of the discourse texts in which real-world events are enacted through linguistic choices made by the reporters or journalists. The unfolding of the re-constructed text in the journalistic discourse involves the deployment of linguistic choices at multiple turns and levels (McCabe and Heilman). Systemic Functional Linguistics (henceforth SFL) proposed by Halliday (1994), views language as a social semiotic resource used by people to express meanings in context. SFL allows the analyst to explore how the linguistic choices interact with the social context to fill the texts with the expressed meanings. Among the assumptions of SFL is that language serves three main purposes:

- the experiential or ideational metafunction, through which language users express their views of the world;

- the interpersonal metafunction, through which users establish and maintain social relationships; and

- the textual metafunction, through which the two previous metafunctions are combined and organised for effectively coherent discourse flow.

An extension of this theory is the Appraisal Framework proposed by Martin and White (2005). According to Martin and White (2005, p. 34), appraisal is one of three major discourse semantic resources construing interpersonal meaning, the other two being involvement and negotiation. The system is divided into three interacting domains - 'engagement', 'attitude', and 'graduation' (see Figure 5.1). Attitude concerns feelings, which include emotional reactions, judgement of behaviour and assessment of things. Engagement deals with the sourcing of attitudes and the play of voices around opinions expressed in discourse. Graduation attends to the grading of phenomena whereby feelings and emotions are intensified and categories are obscured. My focus is on the sub-category of Engagement called 'Entertain'. The Entertain sub-system of the Appraisal framework views authorial locutions not from a truth-functional perspective but from one that sees them as heteroglossic backdrops for the text which emphasise writer's individual subjectivity (Martin and White, 2005, p.105). The Entertain system shifts the focus that drives a text's communicative purpose from being merely 'informational reliability and epistemic status' to one that emphasises the writer's intention of making explicit subjective assessments of the propositions made. The dialogic expansion tools, such as modal verbs, are designed to execute 
locutions, which actively construe a heteroglossic backdrop for a particular text by injecting the author's subjective voice or stance into the proposition. Working from the premise that makes authorial dialogistic positioning the primary determining motive in a proposition, this research was aimed at exploring how the reporters used modal verbs to express their dialogistic voices in the propositions in the news articles with the purpose of 'entertaining' dialogic alternatives with the readership.

\section{Aims of research}

This study was conducted with the aim of identifying how the nine core modal verbs in English were being used to express authorial subjective voices in the news articles in the corpus.

\section{The corpus}

The materials in this corpus revolved around a single event, the launch of RMS Queen Elizabeth, a ship built on the River Clyde in Scotland in 1938. The original texts are kept in the University of Glasgow Archive. These texts formed the electronic corpus in this study comprising 37 newspaper articles which were written by anonymous reporters who focused on the grand Scottish ship and the details of her launch. These reports were drawn from three different sources: The Glasgow Herald (14 issues), The Times (19 issues), and The Scotsman (4 issues).

\section{Related literature review}

Arrese and Perucha (2006) studied the Engagement system in relation to writer stance and to the dimension of subjectivity and inter-subjectivity in English journalistic commentaries and news articles using a refined version of Martin and White's (2005) model. They identified the presence and patterning of the various linguistic resources for the expression of evaluation in these subgenres of journalistic discourse, and established comparisons across language. Their research revealed that whereas journalistic commentaries were clear representations of writers' subjective evaluations and of writer-reader inter-subjective views, news tended to rely on external voices as sources of authority and knowledge. They also found that 'hard' news would represent the extreme position with almost a total lack of expressions of dialogistic positioning (Arrese and Perucha, 2005, p. 246).

Pounds (2010) conducted a study of fourteen hard news articles in English and another fourteen in Italian imbued with negativity for traces of subjectivity in reporting using Martin and White's (2005) Appraisal Framework. Her study found that British hard news reporters appeared to be distant from the facts reported while the Italian reports made more frequent references to the emotive impact of the events on the participating parties (mental and affectual responses and source of attribution) (Pounds, 2010, p. 121). Her analysis of the sub-system in the Engagement system found the Italian reports to be abundant with expressions of uncertainty (perhaps, maybe, possibly . . .).

By investigating resources for Attitude and Engagement in their analysis of a Vietnamese hard newspaper article, Tran and Thomson (2008) demonstrated how a negative portrayal of the US government by the reporter was achieved. Their findings suggested that Vietnamese hard news reporters overtly expressed their subjective assessment of propositions in their reports. Through various expressions of inscribed evaluation and supportive authoritative voices, the reporter had successfully voiced his/her disapproval of US foreign policy. The reporter in their study utilised various compelling voices to endorse his/her authorial position for example, for the American Upper House Committee on Military Force, the commanding division of the American troops in Iraq, and so on.

All of this research has shown insightful findings about journalists' engagement with their readership. However, these studies dealt with modern news materials. The present study, on the other hand, focused on the use of modal verbs by the writers of the historical journalistic texts in this corpus to convey their dialogistic positioning with the readership in the 1930's.

\section{Methodology}

The modality analysis in this study focused on analysing the writers' treatment of the proposition they made in the articles via the study of the use of modality markers as tools of authorial stance. This was done by identifying the Mood choices found in both independent and dependent clauses in the news articles. The analysis also included the identification of the tense elements realised through the Finite of each clause (Gonzalez, 2008, p. 28). 
The foci of the study were the ship and the events revolving around its launch. Therefore only the occurrence of the resources signifying authorial presence and subjectivity in the texts via a dialogic expansive device termed as Entertain, a sub-system within the Engagement framework was emphasised. The use of the nine core modal verbs i.e. 'will', 'would', 'can', 'could', 'shall', 'should', 'may', 'might' and 'must' as modality markers with which this sub-system works was given the major attention.

\section{Findings}

The following explanations about the nine modal verbs which appeared in the texts include examples to show their use as tools of authorial positioning in the corpus of news articles. All clauses in the articles were in the declarative mood choice. The use of the modal auxiliary 'will', which was a median probability or likelihood marker marked the writer's degree of certainty regarding the proposition made in the clause. The modal operator 'could', in contrast, was a resource indicating the writer's endeavour to engage the readers dialogically in the interaction by overtly voicing his subjective stance, acknowledging the fact that his view may not be shared by every reader. The modal 'could' placed the proposition as one of the many propositions in the present communicative context. The example below is taken from the first paragraph of one of the articles.

a. Electrical energy will be so extensively employed in the Queen Elizabeth that apart from her propelling machinery, steam turbines, she could be described as an all-electric ship.

As shown in the example below, the writer used the median scale modal verb 'should' to express the importance of the matter in the proposition.

b. The selection, purchasing, and storing of the vast quantity of perishable foodstuffs and groceries required to provision any other of the Cunard White Star ships, and in due course the Queen Elizabeth, are matters of special interest, since the short time the vessel may be in port, the large number of passengers carried, and the quality of the menus are factors which necessitate that these several affairs should be conducted with expert knowledge, great expedition, and scrupulous care.

As shown in example 6b above, 'may', a low median probability marker, was used to indicate the author's median degree of certainty in the proposition he was making regarding to the duration of the vessel berthing at the port. The use of the high value modality marker 'must' in example $6 \mathrm{c}$ below suggested a strong obligation for the operation of certain technical processes to provide comfort to the passengers. Neither modal verb, however, was deployed as a marker of authorial positioning. This was because the propositions did not involve the readers in a mental debate with the authors as they were merely descriptions of factual and technical procedures.

c. Further, since the great majority of these deck areas are to be used for passengers spaces, in circumstances which make it desirable that some smooth-patterned material shall serve as a background for carpets or rugs, an "under decking" must be laid direct on to the steel, the purpose of this being to provide a flat, even resilient surface...

However, the modal 'must' in example $6 \mathrm{~d}$ below, on the other hand, indicated a strong degree of authorial assertion here with regard to the proposition he was making in the text.

d. For the present, it must serve to state that to ensure that two vessels approaching one another on courses.... In examples 6e below, another marker of authorial positioning is shown through the use of the modal 'might' where the writer injected his personal assessment in the proposition.

e. Special mention might be made of the air preheating sections of these boilers...

The modal 'would', which appeared twice, carried the function as an authorial tool of positioning as shown in example $6 f$ below. Here the author is seen as engaging the readers dialogically by inserting his personal assessment in the proposition.

f. It would therefore be difficult to guess the speed capabilities of the Queen Elizabeth when she is completed. The low value modality markers 'can' (examples $6 \mathrm{~g}$ below), indicated the reporters' weak attempts to entertain the dialogic alternative positions of the readers in the message who may not share his viewpoint on the proposition, namely the pressing need for the construction of a liner as great as the RMS Queen Elizabeth.

g. For the proper maintenance of the two-ship service, however, as Sir Percy Bates has stated, liners are needed that can steam twenty-seven $1 / 2$ knots, and the provision of a companion vessel capable of that speed could not be long delayed. 


\section{Discussion}

The analysis of the Mood and modality in the texts showed that all the clauses were in the declarative. Based on the assessment of the Mood blocks in the texts, which formed the interpersonal perspective and were central to the arguability of the clause, the declarative mood choice were statements offering information that were construed by the writers as not likely to be challenged by its readership. Despite being categorised as hard news articles, which are typically claimed to be objectively written (Bell, 1991), the reports in the corpus were imbued with the authors' subjective assessment of the propositions.

The presence of several modal markers signifies the author's subjective assessment of the message made by engaging readers in the communicative context. The use of modal verbs allows the writers to engage the readers dialogically in the subjective assessment of any proposition. The past and past perfect tenses were used to simply describe occurrences initiated and completed in the past while the present tense indicated the current and immediate affairs of interest. Occasionally, the future form of the verb was used to indicate future planned activities.

In general, my findings did not coincide with Pounds' (2010, p. 121) research that found British hard news reporters to be distant in the delivery of propositions as opposed to the Italian reporters. Her conclusions about the authorial distance in the British hard news articles were not reflected in my findings. This may be attributed to the difference in content or Field of the sets of data. My corpus reported on the highlights of a product's features and events surrounding the launch of a ship with lavish use of authorial positive assessments of the news items while Pounds' study dealt with reports of unfortunate events. Another possible factor was due to the changes of reporting style over time. The reporting style of today's journalistic texts may not be applicable to my data due to the differences in the values upheld by the community of reporters in both eras. Due to the historical nature of my data, it was possible that the reporting style found in my analysis may have been a common journalistic writing practice at that time. However, the diachronic changes in reporting style were not within the scope of this research and were not discussed in depth here.

\section{Conclusion}

The lexico-grammatical investigation has shown that the writers were dependent on various modal verbs to mark their presence and expressions of dialogistic positioning while simultaneously engaging the readership in the propositions. However, it is also important to note that some of these modal verbs function mainly as indicators of possibility, ability or permission. This suggests that the modal verbs in the journalistic texts in my corpus were used for various functions. Although this study did not focus on the use of evaluative language in the texts, the newspaper articles in my corpus were filled with a generous amount of expressions of praise and admiration for the ship. This was evident from the reporters' favourable assessment of the subject matter from the abundant positive evaluative adjectives. The findings here echoed Pounds' statement that all journalism was ultimately opinion journalism in that it was always possible to detect signs of authorial stance even in so-called 'hard-news reporting' which was clearly marked as such, e.g. by 'news' or 'report' in English (2010, p. 107).

\section{References}

Arrese, J.I.M. and Perucha, B.N., (2006). Evaluation and engagement in journalistic commentary and news reportage. Revista Alicantina de Estudios Ingleses, 19, 225-248.

Bell, A., (1991). The language of news media. Oxford: Blackwell.

Gonzalez, E., (2008). The language of the university: A systemic functional analysis. Master dissertation. The University of Texas at Arlington.

Halliday, M.A.K., 1994. An introduction to functional grammar. (2nd ed). London: Edward Arnold.

Halliday, M.A.K. and Matthiessen, C., (2004). An introduction to functional grammar. (3rd ed). London: Hodder Education.

Martin, J.R. and White, P.R.R., (2005). The evaluation of language: Appraisal in English, Hampshire: Palgrave Macmillan.

McCabe, A. and Heilman, K., (2007). Textual and interpersonal differences between a news report and an editorial. Revista Alicantina de Estudios Ingleses, 20, 139-156.

Pounds, G., (2010). Attitude and subjectivity in Italian and British hard-news reporting: The construction of a culture-specific "reporter" voice. Discourse Studies, 12(1), 106-137.

Tran, V.T.H. and Thomson, E., (2008). The nature of 'reporter voice' in a Vietnamese hard news story. University of Wollongong Research Online. Retrieved from <http://ro.uow.edu.au/artspapers/184> 